\title{
El Paleolítico Superior en el Sur de Cádiz
}

\author{
Martí Mas Cornellà y Sergio Ripoll López \\ Departamento de Prehistoria e Historia Antigua de la UNED
}

Durante los últimos años el conocimiento del Paleolítico Superior en Andalucía Occidental ha aumentado considerablemente a partir de los nuevos datos obtenidos en diferentes proyectos de investigación arqueológica que se han venido desarrollando. En este sentido presentamos una síntesis de los resultados aportados en el marco del proyecto Las manifestaciones rupestres prehistóricas de la zona gaditana, actividades arqueológicas autorizadas y subvencionadas por la Dirección General de Bienes Culturales de la Consejería de Cultura y Medio Ambiente de la Junta de Andalucía, que se ocupa de la investigación (Mas Cornellà y Torra Colell, 1990; Mas Cornellà, 1993), realizando una nueva documentación, de las representaciones pintadas o grabadas localizables en los abrigos rocosos de las sierras, constituidas por areniscas silíceas, del Campo de Gibraltar y áreas próximas a la antigua Laguna de la Janda, en donde encontramos conjuntos rupestres tan destacables como los del Tajo de las Figuras, Cuevas los Ladrones o Pretinas, Abrigos de Bacinete o Cuevas de Palomas, dados a conocer a principios de siglo por J. Cabré, E. Hernández-Pacheco, H. Breuil, M. C. Burkitt y W. Verner (Cabré y Hernández-Pacheco, 1914; Breuil y Burkitt, 1929).

\section{CULTURA MATERIAL}

En 1990 una prospección arqueológica superficial (Mas Cornellà y Sanchidrián Torti, 1990), realizada con la finalidad de aproximarnos al prácticamente desconocido contexto arqueológico de las pinturas rupestres ejecutadas en los abrigos de Sierra Momia, nos reveló la existencia de dos yacimientos al aire libre de un interés inesperado, que ofrecían un importante caudal de información y cuya distribución espacial se veía constreñida a áreas muy reducidas. Se trata de la Cubeta de la Paja, dentro del 
Conjunto rupestre del Tajo de las Figuras, y las Cuevas de Levante, lugares situados en Sierra Momia (Benalup). Del conjunto global de las colecciones líticas y su deposición planteamos como hipótesis de trabajo que la funcionalidad de los yacimientos estaría acorde con los patrones de asentamientos estacionales destinados fundamentalmente al abastecimiento de recursos pétreos y su manufactura y los encuadramos cronológicamente en fases avanzadas del Solutrense Evolucionado Ibérico.

En 1991 llevamos a cabo una actuación de urgencia (Ripoll López et al., en prensa) con el fin de diagnosticar y matizar el estado de la cuestión y plantear la intervención más idónea en función de la problemática en torno a la conservación de estos lugares. Un sondeo estratigráfico en las Cuevas de Levante y el análisis de la serie industrial confirmaron el encuadre Solutrense. Aunque la memoria definitiva de estos trabajos está todavía en fase de elaboración, podemos avanzar algunos datos.

La serie industrial analizada nos muestra que el índice de raspadores alcanza un porcentaje del I.R. $=25,93 \%$, mientras que el de los buriles lo supera ampliamente (I.B. $=46,30 \%)$. En cuanto a los índices restringidos de los buriles diedros de ángulo (I.B.d. $(r)=46,30 \%$ ) y el de los buriles sobre truncatura (I.B.t. $(r)=35,19 \%$ ), vemos que son relativamente similares.

El índice de los útiles realizados sobre hojitas únicamente representa un $9,26 \%$ (I.h.). Sin embargo el grupo de útiles que de alguna forma puede caracterizar este conjunto industrial es el solutrense, que aunque posee un bajo porcentaje (I.G.S. $=5,56 \%$ ), junto con el grupo de los buriles y el de las hojitas, nos permite encuadrar este nivel en un horizonte cultural del Solutrense Superior Evolucionado.

Como ya se ha propuesto en otras publicaciones (Ripoll López, 1988, 1989, 1991 y en prensa), un encuadre tan concreto únicamente se puede efectuar cuando se posee una serie industrial suficientemente ámplia, y éste no es el caso, ya que se trata de un reducido sondeo estratigráfico provisional.

Pero creemos poder adelantar que dada la existencia de una punta de aletas y pedúnculo, de una punta de muesca y de una pieza solutrense bifacial -a pesar de que todas ellas aparecen fracturadas-, que su encuadre cultural Solutrense es bastante acertado.

Por otra parte, la existencia de un índice tan alto de buriles, junto con las escasas hojitas, nos podría hacer pensar que se trata de un nivel Magdaleniense, pero la presencia de las piezas antes mencionadas nos ratifica en el encuadre cultural propuesto. Opinamos (Ripoll López, 1988, 1989,1991 y en prensa) que en la zona andaluza -dónde la existencia 
del Magdaleniense Inicial y Medio no está atestiguada- estos estadios culturales se verían sustituidos por el Solutrense Superior Evolucionado.

De cualquier forma el presente artículo es un avance al estudio y además somos conscientes de la reducida superficie excavada, así como de la relativamente breve serie industrial analizada.

\section{ARTE RUPESTRE}

Durante la campaña de 1991, al observar nuevamente los paneles pintados de la Cueva del Tajo de las Figuras nos dimos cuenta de la existencia de un gran número de grabados que habían pasado desapercibidos a anteriores investigaciones (Ripoll López et al., 1991; Mas Cornellà, en prensa; Mas Cornellà y Ripoll López, en prensa). Se trata de tres motivos figurativos - cérvido, équido y cáprido-y otros trazos que no podemos definir formalmente. Los posibles paralelos estilísticos nos llevan a situar estas representaciones en un momento Solutrense sensu lato. Éste encuadre paleolítico queda reafirmado al encontrarse infrapuestas a toda la secuencia pictográfica postpaleolítica, lo cual ratifica su antigüedad, que viene avalada también por los yacimientos próximos a los que nos hemos referido anteriormente.

Durante los trabajos de campo de 1992 (Mas Cornellà, 1993) se revisaron y estudiaron un importante número de nuevas cavidades, localizando otros grabados probablemente paleolíticos en tres abrigos rocosos conocidos por sus pinturas postpaleolíticas, la Cueva del Arco, dentro del Conjunto rupestre del Tajo de las Figuras, y las Cuevas de Levante (dos cavidades) - como puede verse coinciden los dos lugares en donde hemos localizado los yacimientos al aire libre con los grabados que aparecen en cavidades cercanas-, cuyo análisis en profundidad aún no hemos finalizado. Puede destacarse, sin embargo, que se trata de unos trazos finos, largos, horizontales y curvados, uno de ellos infrapuesto a diferentes motivos pintados de la Cueva del Arco y un posible zoomorfo, unas líneas irregulares trazadas verticalmente, varias cazoletas y un triángulo, en este caso muy próximo a las pinturas, de las Cuevas de Levante. Éstas constituyen un complejo de cavidades (abrigos rocosos) y los grabados se sitúan en la conocida por sus pinturas y en la contigua.

Presentamos aquí un estado de la cuestión, que esperamos poder ampliar en futuras investigaciones y trabajos de campo, en relación al conocimiento del Paleolítico Superior de esta zona, del que sólo se poseían escasos, y en algunos casos conflictivos, datos del nivel B de Gorham's Cave (Gibraltar) 
(Waechter, 1953, 1964), de las pinturas de Cueva de Palomas I (Facinas, Tarifa) (Breuil y Burkitt, 1929:53; Breuil, 1974:145; Fortea Pérez, 1978:145; Santiago Vílchez, 1979-1980; Sanchidrián Torti y Mas Cornellà, en prensa) y de las de St Michel's Cave (Gibraltar) (Breuil, 1921:241; 1922:53).

\section{BIBLIOGRAFÍA}

BREUIL, H., 1921, "Nouvelles cavernes ornées paléolithiques dans la province de Malaga", L'Anthropologie, XXXI, Paris, págs. 239-253.

- 1922, "Palaeolithic man at Gibraltar: new and old facts». The Journal of the Royal Anthropological Institute of Great Britain and Ireland, LII, Londres, págs. 46-54.

- 1974, Quatre cents siècles d'art pariétal. Les cavernes ornées de l'age du renne, Editions Max Fourny Art et Industrie, Paris, 413 pág.

BREUIL, H. y BURKITT, M. C., 1929, Rock paintings of Southern Andalusia. A description of a Neolithic and Copper Age art group, Clarendon Press, Oxford, XII + 88 pág.

CABRÉ, Juan y Hernández-PACHECO, Eduardo, 1914, "Avance al estudio de las pinturas prehistóricas del extremo Sur de España (Laguna de la Janda)», Trabajos de la Comisión de Investigaciones Paleontológicas y Prehistóricas, 3, Madrid, 35 pág.

Fortea Pérez, F. J., 1978, “Arte paleolítico del Mediterráneo español», Trabajos de Prehistoria, 35, Madrid, págs. 99-149.

MAS CORNELLÀ, Martí, 1993, «Proyecto: Las manifestaciones rupestres prehistóricas en la zona gaditana. El arte prehistórico en las sierras del Campo de Gibraltar», (Juan M. CAMOS CarRasco y Francisco Nocete Calvo, editores): Investigaciones arqueológicas en Andalucia, 1985-1992. Proyectos, Dirección General de Bienes Culturales de la Consejería de Cultura y Medio Ambiente de la Junta de Andalucía, Huelva, págs. 263-271.

- en prensa, "Documentación e investigación de las manifestaciones artísticas en las Cuevas de Palomas, Abrigos de Bacinete y Conjunto rupestre del Tajo de las Figuras (Cádiz)", Anuario Arqueológico de Andalucía, 1991, Sevilla.

MAS CORNELLÀ, Martí y RIPOLl LóPEz, Sergio, en prensa, "Los grabados rupestres de Cádiz", Actes del ler Congrés Internacional de Gravats Rupestres y Murals (Homenatge a Lluís Diez-Coronel). Lleida, novembre 1992, Institut d'Estudis llerdencs, Lleida.

Mas CORNElLÀ, Martí y SANChidRIÁN TORTI, José Luis, 1990, «Proyecto de investigación arqueológica Las manifestaciones rupestres prehistóricas de la zona gaditana. 1990: Prospección arqueológica superficial en las Cuevas de Levante y el Conjunto rupestre del Tajo de las Figuras (Sierra Momia)", Anuario Arqueológico de Andalucía, 1990. II: Actividades Sistemáticas. Informes y Memorias, Sevilla, págs. 359-370.

Mas Cornellà, Martí y Torra Colell, Guadalupe, 1990, “Arte rupestre en Cádiz. Documentación e investigación", Revista de Arqueología, 113, Madrid, págs. 14-22.

RIPOLl López, Sergio, 1988, «La Cueva de Ambrosio (Vélez-Blanco, Almería) y su posición cronoestratigráfica en el Mediterráneo Occidental», British Archaeological Report, 462 (2 vols.), Oxford, 596 pág.

- 1989, «Le gisement de La Cueva de Ambrosio: Nouveaux apports au Solutréen de la Péninsule Ibérique», L'Anthropologie, 92, París, págs. 851-886.

- 1991, "Le solutréen dans le Sud de la Péninsule lbérique", Colloque International sur les industries à pointes foliacées du Paléolithique supérieur européen, organizado por el Instytut Archeologii Universytet Jagiellonski, en Cracovia (Polonia), 25 de Septiembre a 10 de Octubre de 1989, Les feuilles de pierre, E.R.A.U.L., 42, Liège, págs. 449-465.

- en prensa, "Die stratigraphisch-zeitliche Einordnung der Cueva de Ambrosio in Almería, (Südspanien)", Congreso Internacional de la Unión Internacional de Ciencias Prehistóricas y Protohistóricas (U.I.S.P.P.), Mainz 1987.

Ripoll lópez, Sergio, Mas Cornellà, Marí y Perdigones Moreno, Lorenzo, en prensa, «Actuaciones de urgencia en las Cuevas de Levante y Cubeta de la Paja (Sierra Momia, Benalup, Cádiz)", Anuario Arqueológico de Andalucía, 1991. III: Actividades de Urgencia. Informes y Memorias, Sevilla. 
Ripoll lópez, Sergio, Mas Cornellà, Marti y Torra Colell, Guadalupe, 1991, «Grabados paleolíticos en la Cueva del Tajo de las Figuras (Benalup)", Espacio, Tiempo y Forma. Serie I: Prehistoria y Arqueologia, 4, Madrid, págs. 111-126.

SanChIDRIÁN TORTI, José Luis y MAS CORNELLA, Martí, en prensa, "Discusiones en torno al considerado arte paleolítico del Campo de Gibraltar (Cádiz)", (Eduardo RIPOLL PERELLO, editor): Actas del II Congreso Internacional El Estrecho de Gibraltar. Ceuta, Noviembre 1990, Universidad Nacional de Educación a Distancia, Madrid.

Santiago Vilchez, José M., 1979-1980, «La Cueva de las Palomas en el arte paleolítico del Sur de España", Boletín del Museo de Cádiz, II, Cádiz, págs. 5-11.

WAECHTER, John, 1953, "The excavation of Gorham's Cave and its relation to the prehistory of Southern Spain", Archivo de Prehistoria Levantina, IV, Valencia (Homenaje a D. Isidro Ballester Tormo), págs. 21-24.

- 1964, "The excavation of Gorham's Cave, Gibraltar, 1951-54", Bulletin of the Institute of Archaeology, 4, Londres, págs. 189-221. 